\title{
Statistical Analysis of Reinforced Concrete Bridge Defects for Optimum Maintenance Planning and Budgeting
}

\author{
A. Abdul-Ameer and K. Alhefeiti \\ The British University in Dubai, PO Box 345015, Dubai, UAE
}

\begin{abstract}
Concrete degradation is arguably the main restriction on longevity of service life of buildings and infrastructure, most developed economies spend more on rehabilitation of existing structures than on new one. Concrete can be damaged by a range of chemical, physical and biological cause that include; fire, sea water, aggressive environment, corrosion of reinforcement, impact, bacterial attach to name a few. There is a continuing argument about the main cause of the premature deterioration of structures containing reinforced concrete, these range from inadequate specification, poor design and detailing, poor workmanship and aggressive environment. By far the biggest cause of deterioration is the corrosion of the steel reinforcement, with its expansive byproducts that result in the cracking and spilling of concrete and can ultimately cause total service life failure of the structure if not checked and remedied. Maintenance engineers face an ever ending problem of when is the optimum time to intervene and rehabilitate a deteriorated structural element or whole structure. Budget restrictions and need to optimize the maintenance cycle. The paper will report on a large database of deterioration records of concrete bridges covering a period of over 60 years and include data from over 400 bridge structures. Statistical analysis were used to estimate the deterioration rates of various reinforced concrete defects in a rage of structural elements and bridge types and to arrive a mean service life of the structure, such service life data can then be used by the maintenance manager to budget and prioritize his maintenance work.
\end{abstract}

\section{Introduction}

Concrete is the most widely used construction material in the bridge structures because of its durability and versatility. The durability of concrete is often challenged by the deterioration, because of which most of the concrete bridges do not serve for the full service life as it is designed for. Deterioration of the concrete bridges has caused great loss in infrastructure maintenance. The increasing number of concrete bridge deterioration has increased the repair, rehabilitation or replacement of these structures in short term in the highway networks of most European and North American countries.

Reinforced concrete bridges are designed to perform satisfactorily for their service life. Depending upon the parameters taken in to account during design, service life of bridges varies 50 to 100 years or even more. Minimum requirements for reinforced concrete structures design can be found in EURO CODE 2. However most of the reinforced structures do not perform well for the period it is designed for, as they deteriorate with time.

There have several research been done [1], [2] \& [3] and several studies are being carried out to identify the root cause of deterioration. Research shows that the main cause of deterioration is corrosion of reinforcing steel [4],
[5] which make structure weak and leads to collapse of structure after certain period if it is left ignored.

\subsection{Deterioration of reinforced concrete}

There are four primary causes of concrete degradation, which include chemical, physical, mechanical and biological issues [6]. Chemical factors are primarily linked to salination as well as acidification in the atmosphere, which can lead to corrosion in the case of steel reinforcements, or hydrolysis of the concrete itself [6]. Physical factors may include any temperature or environmental causes that abrade or erode the structure. Mechanical factors may include the amount of load that is placed on the structure, which can induce cracking and the movement of external fluids or grit into these cracks, which can result in breaks. Finally, when there is a possibility of moss, ivy or fungi to have an impact on the structure, among other similar materials, this is a biological factor [6]. Many of these factors may overlap or have an effect on one another, as well [7]. This is due to the fact that concrete is extremely porous and therefore when there is a corrosive or physical effect on the material it is likely to face structural failure [7]. 


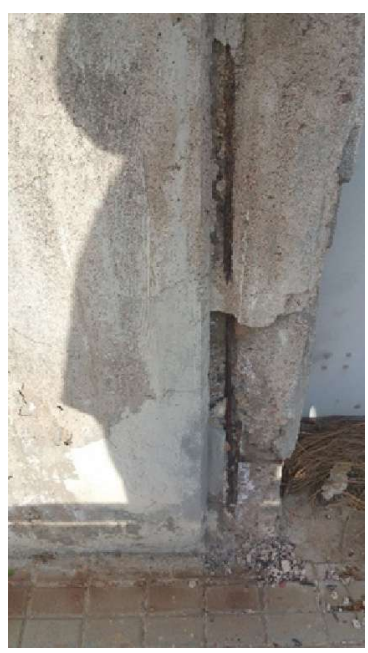

Fig. 1: Damage to a Concrete Wall Caused by Reinforcement Corrosion

Climate change can have a significant effect on all of these factors, which needs to be taken into account now more than ever [8]. As there are more frequent shifts in temperature, an increase in extreme weather events, and unpredictable changes in certain areas of the world and in microclimates, there is a need to recognise that this can have an effect on the way that concrete reacts, and also this can make an impact on the biological factors that may come into play, as these may be very different from in the past [8], [9].

The use of steel reinforcement also has an impact on the way that concrete degrades. Corrosion may be able to decrease the structural capacity of the concrete as a whole through decreasing the cross sectional area of steel reinforcement, which is at an increased risk when it comes to managing the greater loads that are expected in pre-stressed concrete structures [7].

In other words, when it comes to the evaluation of the factors that lead to concrete degradation, it is important to take into context the impact of different materials on the process. Steel is especially problematic, as well, in areas with shifting climate change effects because of its temperature effects relative to the concrete itself [8], [9]. Whereas concrete will erode during temperature changes, the expansion and contraction of steel may increase cracks as well as erosion, but could also lead to structural breaks [6].

\subsection{Existing service life models}

Service life model is the mathematical presentations that show the service life of a structure as a function of different design parameters. They are often derived from degradation or performance models when limit states of maximum degradation or minimum performance are known. Service life models are the very important tools in the bridge management system as well as an engineering infrastructures management. A service life models helps in following:
- Predicting the time it takes to reach relevant limit states for different design and maintenance options.

- Ensuring safety, serviceability \& functionality.

- Evaluating life cycle costs-optimize design, inspection and maintenance.

Because of its importance in structures management many research has been under taken in the service life prediction models. Many approaches have been put forward to estimate the service life concrete structures. According to [10] up to date they are based on the concept of delay time, factor method or stochastic/ probabilistic approach. Redmond [11] has well explained about the delay time modelling of the growth of the defects in concrete bridges components. Likewise many researchers have explained about the factor method and probabilistic approach of service life prediction models.

Clifton [12] has given a good review of methods for predicting the service life of concrete. According to him all these developed methods of concrete service life estimation are subjected to concrete deterioration processes and are based on the following points, which sometimes they may be used in combination of each other.

I. Experience

II. Performance of similar materials

III. Accelerated testing

IV. Mathematical modelling based on chemistry and physics of degradation processes.

V. Application of reliability and stochastic concepts.

Lounis [13] has identified several existing service life models to date in his report "A Probabilistic cumulative damage model for service life prediction of concrete structures" they are: a) Empirical models (accelerated life aging) ; b) Heuristic models; c) Factorial models; d) Logistic models; e) Mechanistic models; f) Cumulative damage models; g) Shock models; h) Probabilistic models. Generally, however, service life prediction models developed for concrete bridges are based on either a deterministic or a probabilistic approach and the corresponding models are called as deterministic models $\&$ probabilistic/stochastic model.

\subsection{Regression model}

Most of the developed degradation models are complex and expensive. They predict deterioration rates by deriving a physical degradation process, which are developed by large amount of test data collected from expensive physical testing. Hence these are not feasible for the modelling deterioration of bridges. There are some alternative models which use historical inspection records. Hence are more feasible than the previous one. The most commonly used concrete bridge deterioration model by the Bridge Management System (BMS) based on historical inspection data are:
I. Regression Model
II. Markovian Model
III. Factor Method 
Regression analysis is primarily used to find the bestfitted mathematical model, so that a dependent or response variable can be predicted from independent or predictor variable(s). Descriptions and controls of the cause-and-effect relationship between variables are also major purposes that regression analysis serves. However, conventional regression techniques are suitable for dealing with non-fuzzy data. A detail evaluation about this model has been done by [13]. A commonly used regression model is the regression function obtained by doing a regression analysis, which was used by [14].

According to Pan [15] among the existing regression model the model proposed by Tanka in 1982 is quite popular and useful, the only problem associated with this model is that it is restricted to symmetric triangular fuzzy numbers. To overcome those problems, a fuzzy least square regression model has developed. However this approach still require considerable computation as in that regression coefficients are derived from non- linear programming problem.

To overcome these problem of complex mathematical computations and asymmetric \& symmetric triangular membership functions, Pan [15] have proposed matrix driven multiple fuzzy linear regression model. They use matrix algebra as the calculation tool which makes the model comparatively simpler to follow and easy to apply than other existing regression model. In the paper "Estimating bridge performance based on a matrix-driven fuzzy linear regression model " published in 2009, Pan [15] have explained about this model and have used for the estimation of overall bridge condition in Taiwan by using bridge inspection data.

\section{Extensive analysis of the database}

The bridge database consists of massive information gathered from the bridge inspections. In order to determine the most useful data, an extensive analysis was under taken. During this process in order to determine the natural deterioration of the structures over their service life, the records of inspection which only relates to the first occurrence of the defect observed were used and the records related with the inspection carried out after remedial measures were not used.

At first the data was analysed to determine the total number of the structures and their corresponding members. The overall data were then analysed on the basis defect type and its frequency of occurrence.

In order to determine the change of the defects with time, the database was again analysed. The records were organised according to their age at inspection and exposure condition. Then they were grouped into ten year intervals. Bridges under mild and moderate and severe exposure were investigated and then a bar chart was produced to show the proportion of defects in each time interval on the basis of the exposure condition.

\section{3 deterioration of the structure}

The main part of the analysis of the database is to investigate the degradation of various structures and their corresponding members over their service life. The main cause of the deterioration was found to be due to corrosion cause by chloride attack or carbonation. Chloride attack was found to be the severe cause of deterioration which arises due to use of de-icing salt .During the analysis following steps were carried out:

I. The inspection records were sorted into groups according to structure type and then to member type.

II. Each group was divided into sub-groups representing the five possible condition states described in Section 4.2.1.3.

III. The average age for each sub-group of records was calculated and used to chart the deterioration of the structure types over their service lives.

By organising, the main data was group according to the exposure type recorded and repeating steps (1) to (3) then the effects of exposure conditions on the deterioration of the structures were investigated.

\section{Statistical analysis of bridge deterioration}

The distribution of possible cause was studies in fig. 2 . The cause was not known in $93.0 \%$ of the cases. Impact $(4.2 \%)$ is the main cause of fault/defect. The reason for this was the fact that the inspectors are not trained engineers and only indicated cause where the reason was obvious, such as bomb damage, impact or clear indication of de-icing salts.

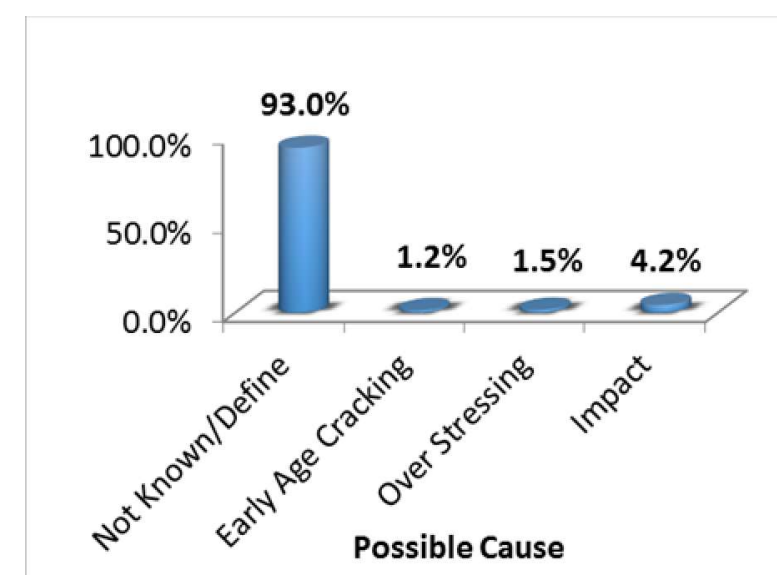

Fig. 2, Distribution of Possible Cause

The distribution of member type was studies in fig. 3 . Flexural $(47.6 \%)$ was the main type seen in in the study sample followed by compression $(25.5 \%)$. This is to be expected as cracks mainly appear in flexural members, where cracking in the tension zone is the norm.

The exposure condition was studies in fig. 4. About $36.1 \%$ of samples were mild, $53.9 \%$ were moderate and $10.0 \%$ were severe. The severe exposure is normally associated with exposure to de-icing salts for deck 
members of over bridges and pier members in underbridges.

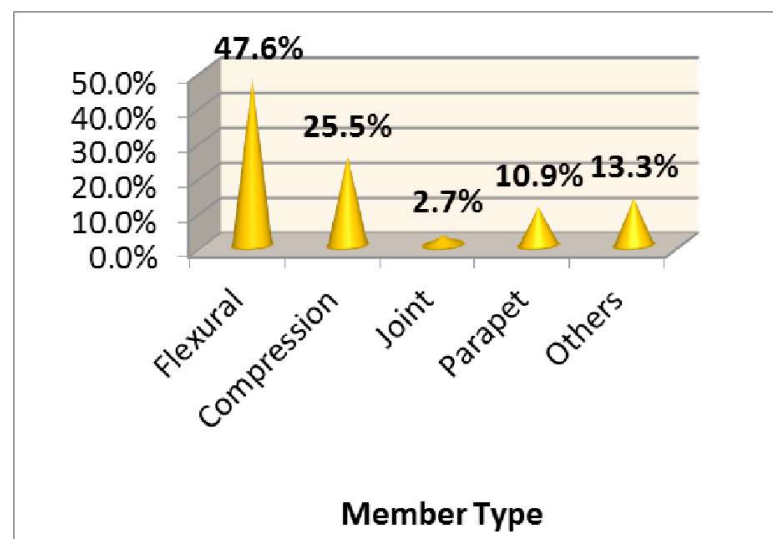

Fig. 3, Distribution of Member Type

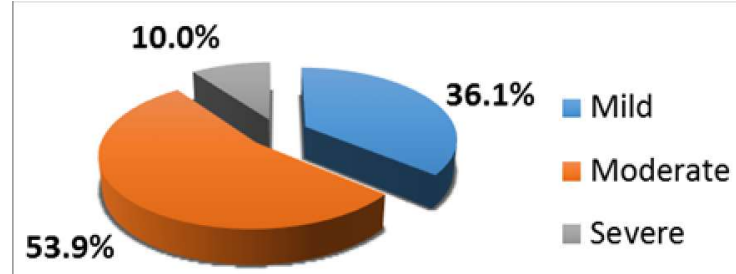

Fig. 4, Distribution of Exposure Condition

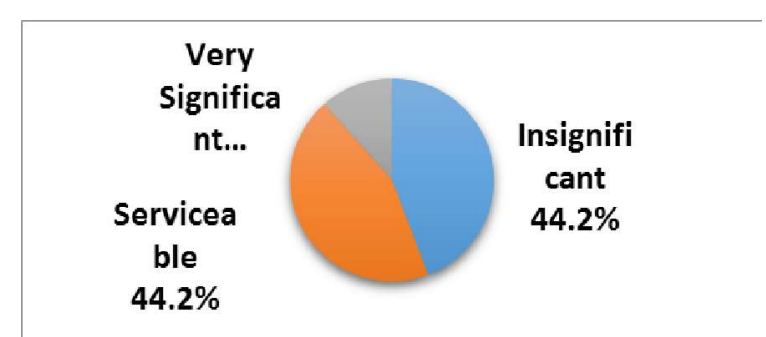

Fig. 5, Distribution of Repair/Urgency Ranking

Repair/urgency ranking was studies in fig. 5. About $44.2 \%$ of samples were insignificant, $44.2 \%$ were serviceable and $11.5 \%$ were very significant. The excellent annual inspection cycle of visual inspections and four yearly principle inspections, kept structures in good state with almost ninety percent in good service condition and only $11 \%$ in significant need for repair. However, this number is significant as the bridge owners have over 5000 bridges and that these are in temperate climate.

Table 1 shows that the average age of building is high in severe spalling (35.9 years with standard deviation 18.5) followed by minor spilling (34.7 years with standard deviation 16.2). The average age of building is 25.8 years with standard deviation 16.2 in multiple cracks $3.0 \mathrm{~mm}$, 23.4 years with standard deviation 16.3 in multiple cracks $1.5 \mathrm{~mm}$ and 20.2 years with standard deviation 16.6 in hairline crack. It is clear that on average, deterioration is fairly rapid from minor spalling to sever spalling, this is to be expected since the removal of parts of the concrete in the minor spalling expose totally the steel to the elements, resulting in an accelerated deterioration.

Table 1, Descriptive Statistics of Building Age in Each Subset

\begin{tabular}{|c|l|l|l|l|l|}
\hline $\begin{array}{l}\text { Descriptive } \\
\text { Statistics }\end{array}$ & $\begin{array}{l}\text { Hairlin } \\
\text { e } \\
\text { Crack }\end{array}$ & $\begin{array}{l}\text { Multiple } \\
\text { Cracks } \\
1.5 \mathrm{~mm}\end{array}$ & $\begin{array}{l}\text { Multiple } \\
\text { Cracks } \\
3.0 \mathrm{~mm}\end{array}$ & $\begin{array}{l}\text { Minor } \\
\text { spalling }\end{array}$ & $\begin{array}{l}\text { Severe } \\
\text { spalling }\end{array}$ \\
\hline Mean & 20.2 & 23.4 & 25.8 & 34.7 & 35.9 \\
\hline Median & 16.0 & 20.0 & 23.5 & 34.5 & 36.5 \\
\hline $\begin{array}{c}\text { Std. } \\
\text { Deviation }\end{array}$ & 16.6 & 16.3 & 16.2 & 16.2 & 18.5 \\
\hline Variance & 276 & 265 & 264 & 262 & 344 \\
\hline Range & 62.0 & 71.0 & 62.0 & 62.0 & 80.0 \\
\hline $\begin{array}{c}\text { Quartile - } \\
\text { Q1 }\end{array}$ & 6.0 & 12.8 & 13.0 & 23.5 & 21.0 \\
\hline $\begin{array}{c}\text { Quartile - } \\
\text { Q2 }\end{array}$ & 16.0 & 20.0 & 23.5 & 34.5 & 36.5 \\
\hline $\begin{array}{c}\text { Quartile - } \\
\text { Q3 }\end{array}$ & 30.5 & 30.0 & 41.3 & 46.3 & 46.5 \\
\hline IQR & 24.5 & 17.3 & 28.3 & 22.8 & 25.5 \\
\hline
\end{tabular}

Table 2, 95\% Confidence Interval of Age in Each Subset

\begin{tabular}{|c|c|c|}
\hline \multirow[b]{2}{*}{ Fault/Defect } & \multicolumn{2}{|c|}{ 95\% Confidence Interval } \\
\hline & Lower Bound & $\begin{array}{l}\text { Upper } \\
\text { Bound }\end{array}$ \\
\hline Hairline Crack & 16.23 & 24.14 \\
\hline Multiple Cracks $1.5 \mathrm{~mm}$ & 19.56 & 27.32 \\
\hline Multiple Cracks 3.0mm & 21.19 & 30.41 \\
\hline Minor spilling & 30.84 & 38.56 \\
\hline Severe Spilling & 31.46 & 40.31 \\
\hline Total & 26.20 & 30.08 \\
\hline
\end{tabular}

Table 2 shows that the severe spilling has the highest lower and upper bounds (31.46-40.31) followed by minor spilling (30.84-38.56). Hairline crack has the $95 \%$ confidence interval $16.23-24.14$, multiple cracks $1.5 \mathrm{~mm}$ has 19.56-27.32 and multiple cracks $3.0 \mathrm{~mm}$ has 21.19 30.41. The almost constant difference between the lower bound and upper bound is indicative of the normal distribution of the sample. Although the different defects has each, large standard deviation, the population of defects is of a normal distribution.

Table 3, Chi-square test to check the independency of subsets

\begin{tabular}{|l|l|l|l|}
\hline Variables & $\begin{array}{l}\text { Chi- } \\
\text { square }\end{array}$ & df & $\begin{array}{l}\mathbf{p}- \\
\text { value }\end{array}$ \\
\hline Possible Cause & 36.055 & 12 & 0.000 \\
\hline Member Type & 33.424 & 16 & 0.006 \\
\hline Exposure Condition & 12.766 & 8 & 0.120 \\
\hline Repair/Urgency Ranking & 67.551 & 8 & 0.000 \\
\hline
\end{tabular}


$\mathrm{H}_{0}$ : possible cause/member type/exposure condition/urgency ranking and fault/defect are independent

$\mathrm{H}_{1}$ : possible cause/member type/exposure condition/urgency ranking and fault/defect are not independent

Table 3 shows the results of chi-square test. Chi-square test was used to check whether possible cause/member type/exposure condition/urgency ranking and subset are independent.

The p-value corresponding to possible cause is less than the significance level 0.05 ; the null hypothesis rejected and accept the alternative hypothesis that the possible cause and fault/defect are not independent. Then can conclude that the possible cause is depends on fault/defect.

The p-value corresponding to member type is less than the significance level 0.05 ; the null hypothesis rejected and accept the alternative hypothesis that the member type and fault/defect are not independent. Then can conclude that the exposure condition is depends on fault/defect.

The $\mathrm{p}$-value corresponding to exposure condition is greater than the significance level 0.05; the null hypothesis accept that the exposure condition and fault/defect are independent. Then can conclude that the exposure condition is not depending on fault/defect.

The p-value corresponding to repair/urgency ranking is less than the significance level 0.05; the null hypothesis rejected and accept the alternative hypothesis that the repair/urgency ranking and fault/defect are not independent. Then can conclude that the repair/urgency ranking is depends on fault/defect.

Table 4: Check the Difference in Age of Building in All Subsets Using ANOVA

\begin{tabular}{|l|l|l|l|l|l|}
\hline & $\begin{array}{l}\text { Sum of } \\
\text { Squares }\end{array}$ & df & $\begin{array}{l}\text { Mean } \\
\text { Square }\end{array}$ & $\begin{array}{l}\text { F - } \\
\text { value }\end{array}$ & $\begin{array}{l}\text { p - } \\
\text { value }\end{array}$ \\
\hline $\begin{array}{l}\text { Between } \\
\text { Groups }\end{array}$ & 13459 & 4 & 3365 & 11.888 & 0.000 \\
\hline $\begin{array}{l}\text { Within } \\
\text { Groups }\end{array}$ & 91990 & 325 & 283 & & \\
\hline Total & 105449 & 329 & & & \\
\hline
\end{tabular}

$\mathrm{H}_{0}$ : the average age of building is same in all subsets

$\mathrm{H}_{1}$ : the average age of building is different in all subsets Table 4 shows the results of analysis of variance (ANOVA). ANOVA was used to check the difference in average age of building in all subsets. Here the p-value is less than the significance level 0.05 ; the null hypothesis reject and accept the alternative hypothesis that the average age of building is different in all subsets. Then can conclude that the age of building is significantly different in each data subsets.

$\mathrm{H}_{0}$ : the average age of building is same between each pair of subset.

$\mathrm{H}_{1}$ : the average age of building is different between each pair of subset.

Table 5 shows the results of independent sample t-test. Independent sample t-test was used to check the difference in average age of building between each pair of subset. The table shows that age in hairline crack is significantly different from minor spilling and severe spilling as the corresponding $p$-values are less than the significance level 0.05 . The age in multiple cracks $1.5 \mathrm{~mm}$ is significantly different from minor spilling and severe spilling as the corresponding $p$-values are less than the significance level 0.05 . The age in multiple cracks $3.0 \mathrm{~mm}$ is significantly different from minor spilling and severe spilling as the corresponding $\mathrm{p}$-values are less than the significance level 0.05 .

Table 5, T-Test to Check the Pair-Wise Difference in Age between Subsets

\begin{tabular}{|l|l|l|l|l|}
\hline Pair & $\begin{array}{l}\text { Mean } \\
\text { Difference }\end{array}$ & $\begin{array}{l}\text { t - } \\
\text { value }\end{array}$ & df & $\begin{array}{l}\text { p - } \\
\text { value }\end{array}$ \\
\hline $\begin{array}{l}\text { Hairline Crack -Multiple } \\
\text { Cracks 1.5mm }\end{array}$ & 3.257 & 1.172 & 138 & 0.243 \\
\hline $\begin{array}{l}\text { Hairline Crack - } \\
\text { Multiple Cracks 3.0mm }\end{array}$ & 5.614 & 1.843 & 118 & 0.068 \\
\hline $\begin{array}{l}\text { Hairline Crack - Minor } \\
\text { Spalling }\end{array}$ & 14.514 & 5.239 & 138 & 0.000 \\
\hline $\begin{array}{l}\text { Hairline Crack - Severe } \\
\text { Spalling }\end{array}$ & 15.700 & 5.277 & 138 & 0.000 \\
\hline $\begin{array}{l}\text { Multiple Cracks 1.5mm - } \\
\text { Multiple Cracks 3.0mm }\end{array}$ & 2.357 & 0.783 & 118 & 0.435 \\
\hline $\begin{array}{l}\text { Multiple Cracks 1.5mm - } \\
\text { Minor Spalling }\end{array}$ & 11.257 & 4.105 & 138 & 0.000 \\
\hline $\begin{array}{l}\text { Multiple Cracks 1.5mm - } \\
\text { Severe Spalling }\end{array}$ & 12.443 & 4.219 & 138 & 0.000 \\
\hline $\begin{array}{l}\text { Multiple Cracks 3.0mm - } \\
\text { Minor Spalling }\end{array}$ & 8.900 & 2.967 & 118 & 0.004 \\
\hline $\begin{array}{l}\text { Multiple Cracks 3.0mm - } \\
\text { Severe Spalling }\end{array}$ & 10.086 & 3.091 & 118 & 0.002 \\
\hline $\begin{array}{l}\text { Minor Spalling -Severe } \\
\text { Spalling }\end{array}$ & 1.186 & 0.403 & 138 & 0.688 \\
\hline
\end{tabular}

\section{General discussion}

The statistical analysis of the database has shown than deterioration of the concrete bridges although is varied and has several causes, it follows a normal distribution. This gives confidence in using the database to draw service life values that can be used in the asset and maintenance management of concrete bridges for an optimum repair and rehabilitation planning of such as important asset in the transport system in question. Although the exposure condition is not always explicitly stated, the statistical values given are a good indication for the exposure condition of these bridges in the temperate climate they exist in.

The value of the annual visual inspection, which is low cost and takes relatively little time is evident in the low percentage of structures in need of major rehabilitation. This inspection is supported by a major principle inspection, where more extensive inspection is conducted and tests carried out where necessary.

The analysis of the data to check the significance of the service life estimates of the various bridges shows that the differences are real and statistically significant. This helps the maintenance engineer in having the confidence in planning and budgeting of the repair and maintenance of his bridge stock and maintaining his assess serviceable 
and functional.

\section{Conclusion}

The hairline crack was started to see when the average age of the building will be at almost 20.2 years. Multiple cracks $1.5 \mathrm{~mm}$ and multiple cracks $3.0 \mathrm{~mm}$ are started to build when the age gone past 23 and 25 years respectively. The spall cases are seen when the building got much older. Minor spilling and severe spilling are started to build when the age will be at 34.7 and 35.9 years respectively.

Age of building in is normally distributed in all faults/defects. Severe spilling has the highest confidence interval for age followed by minor spilling. Possible cause, member type and urgency ranking are dependent with fault/defect and exposure condition is independent. Building age and Building size have no relationship and they are independent. The difference in building age between defects/faults is highly significant.

\section{ACKNOWLEDGMENT}

1. The authors wish to acknowledge the support and encouragement for this research provided by the Vice Chancellor, The British University in DubaiUAE.

2. The authors wish to thank Prof Abid Abu-Tair for providing the historical structures data used in this research.

\section{References}

1. P.T. Lees, Deterioration Mechanism, In Durability of concrete structures. Investigation, repair, protection. Edited by Mays Geoff, E \& FN SPON, an imprint of chapman \& Hall, London, (1992).

2. S. Rostam, Durability of Concrete Structures- The State Of The Art, In: Durability of Materials \& Structures in Building \& Civil Engineering, edited by C.W.Yu \& John W. Bull, Whittles Publishing. CRC press, UK, (2006).

3. A. M. Neville, "Properties of Concrete", In : Properties of concrete, Fourth edition, pp 482-483, London: Longman, (1995).

4. C. B. Mc Parland, A. I. Abu-Tair, A. Nadjai, Modelling Deterioration of Concrete Bridges using a Large Database of Inspection Records, 9th International Conference on Structural Faults and Repair, 'Extending the Life of Bridges, Civil \& Building Structures', London, 4th-6th July, (2001).

5. J. Hu, S. J. Lee, Y. J. Kim and M. Mahgoub, Inspection and Non-destructive Evaluation of Concrete Bridge with Environmental Deterioration.
Climatic Effects on Pavement and Geotechnical Infrastructure, p.193, (2014).

6. S. Loos, Probabilistic Evaluation of Carbonation Induced Deterioration in Prestressed Concrete Structures. Ohio State University Working Paper, (2015).

7. M. G. Stewart, X. Wang, and M. N. Nguyen, Climate change adaptation for corrosion control of concrete infrastructure. Structural Safety, 35, pp.29-39, (2012).

8. X. Wang, M.G. Stewart, and M. N. Nguyen, Impact of climate change on corrosion and damage to concrete infrastructure in Australia. Climatic Change, 110(3-4), pp.941-957, (2012).

9. A. I. Abu-Tair, C. McParland, J. F. Lyness, and A. Nadjai, Predictive Models of Deterioration Rates of Concrete Bridges Using The Factor Method Based on Historic Inspection Data, Paper 262, Proceedings of 9th International Conference on the Durability of Building Materials and Components, Brisbane(9DBMC), Brisbane, Australia, 17-20. March 2002. Paper 262, (2002).

10. D. F. Redmond, A. H. Christer, S. R. Rigden, E. A. Burley, A. Tajelli, and A. I. Abu-Tair, O.R. modelling of the deterioration and maintenance of concrete Structures, European Journal of Operational Research 99 (1997) 619-631, (1997).

11. J. R. Clifton, Predicting the Service Life of Concrete, ACI Materials Journal, Vol. 90, No. 6, 611-617 (1993).

12. Z. Linous, A Probabilistic cumulative damage model for service life prediction of concrete structures, National Research Council Canada, (2007).

13. G. Morcous, H. Rivard, and A. M. Hanna, Predicting the Condition of Bridge Decks Using Case-Based Reasoning, Proceedings of the CSCE 29th Annual Conference, Edited by Noakes, D., Victoria, BC, Canada, June (2001).

14. D. Veshosky, C. R. Beidleman, G. W. Buetow, and M. Demir, Comparative Analysis of Bridge Superstructure Deterioration, ASCE Journal of Structural Engineering, Vol. 120(7), pp. 2123-2136 (1994).

15. Pan, Nang - Fei, Lin, Tzu - Chieh and Pan, Nai Hsin, Estimating bridge performance based on a matrix - driven fuzzy linear regression model, Automation in Construction 18(2009) 578 - 586, (2009).F. De Lillo, F. Cecconi, G. Lacorata, A. Vulpiani, EPL, 84 (2009) 